\title{
태양광발전 단기예측모델 개발
}

\section{The Development of the Short-Term Predict Model for Solar Power Generation}

\author{
김광득* \\ Kim Kwang-Deuk* ${ }^{\dagger}$
}

(Submit date : 2013. 10. 29., Judgment date : 2013. 11. 5., Publication decide date : 2013. 12. 19.)

\begin{abstract}
In this paper, Korea Institute of Energy Research, building integrated renewable energy monitoring system that utilizes solar power generation forecast data forecast model is proposed. Renewable energy integration of real-time monitoring system based on monitoring data were building a database and the database of the weather conditions and to study the correlation structure was tailoring. The weather forecast cloud cover data, generation data, and solar radiation data, a data mining and time series analysis using the method developed models to forecast solar power. The development of solar power in order to forecast model of weather forecast data it is important to secure. To this end, in three hours, including a three-day forecast today Meteorological data were used from the KMA(korea Meteorological Administration) site offers. In order to verify the accuracy of the predicted solar circle for each prediction and the actual environment can be applied to generation and were analyzed.
\end{abstract}

Key Words : 시계열 예측모델(Time series forecast model), 태양광 발전 예측(Predict of solar power generation), 구름기상데이터(Cloud meteorological data), 태양광발전 모니터링(PV monitoring), 데이터 마이닝(Data mining)

\section{기 호 설 명}

$\mathrm{hPa}$

DD

S_time

e_time

sky

wfKor day

hour
: 0:금일, 1: 익일, 2: 2일후

: t: 3 시간간격

\section{1. 서 론}

태양에너지, 풍력 등의 신재생에너지에 대 한 발전량 예측은 설비의 효율뿐만 아니라 기

\footnotetext{
*† 김광득(교신저자) : 한국에너지기술연구원 신재생에너지 *† Kim Kwang-Deuk(corresponding author) : New and Renewable 연구본부

E-mail : kdkime@kier.re.kr, Tel : 042-860-3731 Research Division, Korea Institute of Energy Research

E-mail : kdkim@kier.re.kr, Tel : 042-860-3731
} 
상의 변화에 따른 복합적인 요소가 예측에 많 은 영향을 미치기 때문에 장단기 생산량 예측 이 매우 어려운 분야이다. 본 연구는 $\mathrm{E}$ 연구원 에 구축된 신재생에너지 통합 모니터링 시스템 에서 측정한 데이터를 활용하여 태양에너지의 생산량을 예측할 수 있는 예보 모델을 제시하고 자 한다. 이를 위해 신재생에너지 통합 모니터 링 시스템의 실시간 모니터링 자료와 기상환경 과의 정확한 상관관계를 연구할 수 있는 구조로 연구기반 데이터베이스를 구축하였다. 또한 기 상환경 데이터는 3 시간 단위로 금일 포함 3일간 의 예보데이터를 기상청 사이트로부터 제공받 아 활용하였다. 그리고 예측의 정확성을 검증하 기 위해 각 태양광 발전원에 대한 예측결과와 실 환경 적용 발전량과 비교 분석이 가능하도 록 하였다. 2장의 예측모델개발을 위한 구름 기 상데이터의 분석 및 판정알고리즘 설계를 통해 측정된 발전량 데이터 및 일사량 데이터의 상 관성을 이용한 태양광 예측알고리즘을 개발하 고 시스템구현을 통한 비교분석을 수행하였다.

\section{2. 예 측모델개발을 위한 기상데이터 분석}

태양광 발전 예측에 필요한 기상데이터는 운량 예보와 과거의 운량 데이터이다. 기상청 이 제공하는 운량 예보는 1: 맑음, 2: 구름조 금, 3: 구름 많음, 4: 흐림 이렇게 4단계로 예보 되고 과거 운량 데이터는 맑음 $(0 \leq$ 전운량 $\leq 2)$, 구름조금 $(3 \leq$ 전운량 $\leq 5)$, 구름 많음 $(6 \leq$ 전운량 $\leq 8)$, 흐림 $(9 \leq$ 전운량 $\leq 10)$ 으로 0 부터 10 까지 11 단계로 관측된다[1]. 태양광 발전 예측을 위해서는 과거의 관측 운량 데이터를 예보 단 계와 같이 4단계로 변환한 데이터가 필요하다.

\section{1 기상 예보데이터}

기상 예보데이터를 실시간적으로 수집·활용하
기위해 기상청의 RSS(Really Simple Syndication, Rich Site Summary) 리더기를 설치 활용하였 다. RSS란 블로그(Blog)처럼 콘텐츠(Contents) 업 데이트가 자주 일어나는 웹사이트에서, 업 데이트된 정보를 쉽게 구독자들에게 제공하기 위해 XML을 기초로 만들어진 데이터 형식이다.

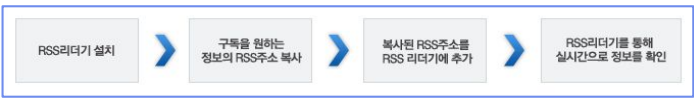

Fig. 1 KMA RSS

$\mathrm{RSS}$ 서비스를 이용하면 업 데이트된 정보를 찾기 위해 홈페이지에 일일이 방문하지 않아 도 업데이트 될 때마다 빠르고 편리하게 확인 할 수 있으며, Fig. 1은 KMA RSS 이용절차 이며, Table 1은 서비스 XML 포맷이다.

\section{2 기상청 예보테이블 및 데이터변환}

기상청 사이트에서 $\mathrm{RSS}$ 로 제공하는 기상예 보 데이터는 Fig. 2와 같은 구조의 테이블로 변환되어 저장된다.

Table 1 XML Format at KMA Service

$<$ ?XML version $=" 1.0^{\prime \prime}$ encoding $=" \mathrm{UTF}-8^{\prime \prime}$ ?

$-<$ wid $>$

- <header $>$

$<\mathrm{tm}>201112262000</ \mathrm{tm}>$

$<\mathrm{y}>125</ \mathrm{y}>$

$</$ header $>$

- <body $>$

- $<$ data seq $=" 0^{\prime \prime}>$

$<$ hour $>24<$ hour $>$

$<$ day $>0</$ day $>$

$<$ temp $>-6.1</$ temp $>$

$<$ tmx $>-999.0</$ tmx $>$

$<$ sky $>1</$ sky $>$

$<$ pty $>0</$ pty $>$

$<$ wfKor $>$ 맑음 </wfKor $>$

$<$ wfEn $>$ Clear $</$ wfEn $>$

$<$ pop $>0</$ pop $>$

$<\mathrm{r} 12>0.0</ \mathrm{r} 12>$

$<\mathrm{s} 12>0.0</ \mathrm{s} 12>$

$<$ ws $>2.5</$ ws $>$

$<\mathrm{wd}\rangle 7</ \mathrm{wd}\rangle$

$<$ wdKor $>$ 북서 </wdKor $>$

$<$ wdEn $>$ NW $</$ wdEn $>$

$<$ reh $>32</$ reh $>$

$</$ data $>$ 


\begin{tabular}{|c|c|c|c|c|c|c|c|c|c|c|}
\hline 날자 & 수집시가 & seq hou & daj & & temp & $\operatorname{tin} x$ & $\mathrm{tmn}$ & sky & wfkor & WEn \\
\hline $2011-09.08$ & $05: 5149$ & 0 & 9 & 0 & 21.8 & 25.7 & -999 & 4 & 0 흐림 & Cloudy \\
\hline $2011-09-08$ & 05.5149 & 1 & 12 & 0 & 23.4 & 25.7 & -999 & 4 & 0 흐림 & Cloudy \\
\hline $2011-09 \cdot 08$ & 05.5149 & 2 & 15 & 0 & 24.7 & 25.7 & -999 & 4 & 0 흐림 & Cloudy \\
\hline $2011-00.08$ & $05: 5149$ & 3 & 18 & 0 & 23.6 & 25.7 & -999 & 4 & 0 흐림 & Cloudy \\
\hline $2011-09-08$ & $05: 5149$ & 4 & 21 & 0 & 22.5 & 25.7 & -999 & 4 & 0 흐림 & Cloudy \\
\hline $2011-09 \cdot 08$ & 05.5149 & 5 & 24 & 0 & 21.5 & 25.7 & .999 .999 & 4 & 0 흐림 & Cloudy \\
\hline $2011-09-08$ & 05.5149 & 6 & 3 & 1 & 20.3 & 24.8 & 19.2 & 4 & 0 흐림 & Cloudy \\
\hline $2011-09 \cdot 08$ & 05.5149 & 7 & 6 & 1 & 20.1 & 24.8 & 19.2 & 4 & 0 흐림 & Cloudy \\
\hline $2011-09 \cdot 08$ & $05: 5149$ & 8 & 9 & 1 & 21.5 & 24.8 & 19.2 & 4 & 0 흐림 & Cloudy \\
\hline $2011-09-08$ & 055149 & 9 & 12 & 1 & 22.7 & 24.8 & 19.2 & 4 & 0 흐림 & Cloudy \\
\hline $2011-09-08$ & 05.5149 & 10 & 15 & 1 & 23.5 & 24.8 & 19.2 & 4 & 0 흐림 & Cloudy \\
\hline $2011-09 \cdot 08$ & 05.5149 & 11 & 18 & 1 & 22.7 & 24.8 & 19.2 & 4 & 0 흐림 & Cloudy \\
\hline $2011-09 \cdot 08$ & 05.5149 & 12 & 21 & 1 & 21.8 & 24.8 & 19.2 & 4 & 0 흐림 & Cloudy \\
\hline $2011-09-08$ & $05: 5149$ & 13 & 24 & 1 & 21.6 & 24.8 & 19.2 & 4 & 0 흐림 & Cloudy \\
\hline $2011-09-08$ & $05: 5149$ & 14 & 3 & 2 & 20.5 & .999 & 19.3 & 4 & 0 흐림 & Cloudy \\
\hline $2011-09-08$ & $05: 5149$ & 15 & 6 & 2 & 20.3 & -999 & 19.3 & 4 & 0 흐림 & Cloudy \\
\hline
\end{tabular}

Fig. 2 Meteorological Predict Table(weather)

위의 데이터 중 day 칼럼의 0 은 금일을 의 미하고 1 은 익일, 2 는 2 일후를 의미하며, hour 칼럼의 3 은 0 시부터 3 시까지, 6 은 3 시부터 6 시 까지의 3 시간을 말한다. 예보 데이터의 운량 의 4 단계는 sky 칼럼으로 되어 있고 이에 대 한 설명 칼럼은 wfKor이다.

태양광 발전의 측정 데이터는 Fig. 3과 같이 특정 시간(1분 간격, 10 분 간격)의 테이블에 저장된다. 그리고 기상 예보 데이터와 연계하 기 위해서 Fig. 4 와 같이 데이터를 변환 저장 해야 한다.

\begin{tabular}{|c|c|c|c|c|}
\hline 8 ipv6 & cpower & powersum & Pidale & Pi lime \\
\hline 2001:268:ee:100:22:fffe00:1 & 0.55 & 3813.00 & $2012 \cdot 08 \cdot 01$ & $12: 00$ \\
\hline 2001:268:ee:100:22:1ffe000:1 & 0.55 & 3813.00 & 2012.08 .01 & $12: 10$ \\
\hline 2001:2b8:ee:100:22:tffe000:1 & 0.56 & 3813.00 & $2012 \cdot 08 \cdot 01$ & $12: 20$ \\
\hline 2001:268:ee:100:22:fffec00:1 & 0.56 & 3813.00 & $2012: 08.01$ & $12: 30$ \\
\hline 2001:268:ee:100:22:1ffee00:1 & 0.53 & 3813.00 & 2012.08 .01 & 1240 \\
\hline 2001:268:ee:100:22:1ffe000:1 & 0.54 & 3813.00 & 2012.08 .01 & $12: 50$ \\
\hline 2001:268:ee:100:22:fiffe000:1 & 0.55 & 3814.00 & 2012.08 .01 & $13: 00$ \\
\hline 2001:2b8:ee:100:22:fffe000:1 & 0.51 & 3814.00 & $2012.08 \cdot 01$ & $13: 10$ \\
\hline 2001:268:ee:100:22:fffe000:1 & 0.47 & 3814.00 & 2012.0801 & $13: 20$ \\
\hline
\end{tabular}

Fig. 3 PV Power Generation Table(rnpower10)

또한 발전량 테이블인 rnpower10과 조인 쿼리가 이루어 질 수 있도록 weather 테이블 의 hour를 시작시간 s_time, 종료시간 e_time 으로 변환하여 테이블에 저장한다.

\begin{tabular}{|c|c|c|c|c|c|c|c|c|}
\hline$P$ i idde & is stine & $P_{\text {e_tme }}$ & lenp & $\operatorname{tm} x$ & $\mathrm{tm}$ & sky & ply willor & weEn \\
\hline 201200.01 & 00:00 & 0300 & 26 & 35 & 25 & 2 & 0 구를 조흠 & Litille Cloudy \\
\hline 20120001 & $03: 00$ & 060 & 26 & 35 & 25 & 2 & 0 구름 조금 & Litile Cloudy \\
\hline 2012060.01 & 06:00 & 0900 & 30 & 35 & . 9999 & 2 & 0 구를 조금 & Litle Claudy \\
\hline 2012:0601 & $09: 00$ & 1200 & 32 & 35 & .999 & 2 & 0 구를 조금 & Litlle Claudy \\
\hline $2012: 00.01$ & 12:00 & 1500 & 35 & 35 & .999 & 2 & 0 구를 조흠 & Litile Cloudy \\
\hline 20120001 & $15: 00$ & 180 & 33 & .999 & .999 & 2 & 0 구름 조금 & Litille Cloudy \\
\hline $2012: 0.001$ & 18:00 & 21:00 & 31 & .999 & .999 & 2 & 0 구름 조금 & Litlle Claudy \\
\hline 2012000.01 & 21:00 & 2400 & 28 & .999 & .999 & 2 & 0 구를 조금 & Litle Claudy \\
\hline $2012: 00.02$ & 00:00 & 0300 & 27 & 35 & 26 & 2 & 0 구틀 조금 & Litille Cloudy \\
\hline 20120002 & $03: 00$ & 060 & 26 & 35 & 26 & 2 & 0 구름 조금 & Litile Cloudy \\
\hline 2012080.02 & 06:00 & 0900 & 30 & 35 & .999 & 3 & 0 구름 많음 & Mosily flaudy \\
\hline 201200.02 & $09: 00$ & 1200 & 33 & 35 & .999 & 3 & 0 구름 많음 & Mosily Clauty \\
\hline $2012: 0802$ & $12: 00$ & 1500 & 35 & 35 & .999 & 3 & 0 구를 많음 & Mossyy ylaudy \\
\hline 20120002 & $15: 00$ & 180 & 33 & .999 & .999 & 3 & 0 구름 많음 & Mosily claudy \\
\hline 2012080.02 & 18:00 & $21: 00$ & 30 & .999 & .999 & 3 & 0 구름 많음 & Mosily flaudy \\
\hline $2012: 0.02$ & 21:00 & 2400 & 28 & .999 & .999 & 3 & 0 구름 많음 & Mosily Claudy \\
\hline $2012: 0.003$ & 00:00 & 0300 & 27 & 36 & 26 & 2 & 0 구를 조금 & Litille Cloudy \\
\hline 20120003 & 03.00 & 0600 & 26 & 36 & 26 & 2 & 0 구름 조금 & Litille Cloudy \\
\hline 201208.03 & $06: 00$ & 0900 & 30 & 36 & .999 & 2 & 0 구름 조금 & Litle Cloudy \\
\hline 2012:06:-03 & 09:00 & 1200 & 33 & 36 & .999 & 2 & 0 구를 조금 & Litile Cloudy \\
\hline $2012: 0.003$ & 12:00 & 1500 & 35 & 36 & .999 & 3 & 0 구를 많음 & Mossyy ylauds \\
\hline 20126003 & 15.00 & 1800 & 34 & .999 & .999 & 2 & 0 구름 조금 & Litle Eloudy \\
\hline $2012 \cdot 0.0 .03$ & 18:00 & $21: 00$ & 31 & .999 & .999 & 2 & 0 구ㄹㅡㅡ 조금 & Litille Claudy \\
\hline $2012: 00.03$ & 21:00 & 2400 & 28 & .999 & -999 & 2 & 0 구를 조금 & Litlle Claudy \\
\hline $2012 \cdot 0.04$ & $00: 00$ & 0300 & 27 & 36 & 25 & 2 & 0 구를 조흠 & Litille Cloudy \\
\hline 20120604 & $03: 00$ & 060 & 26 & 36 & 25 & 2 & 0 구름 조금 & Litlle Cloudy \\
\hline
\end{tabular}

Fig. 4 Converted Cloud Table(wforecast)

\section{3 운량관측 데이터 및 판정 알고리즘}

운량 관측 데이터는 11 가지 단계를 가짐으 로 예보데이터와는 다른 구조로 되어 있어 발 전량 예측을 위해서는 과거 운량 관측 데이터 를 예보 데이터와 같은 구조로 변환하는 것이 필요하다.

하늘상태는 전운량을 4 등분하여 맑음 $(0 \leq$ 전운량 $\leq 2)$, 구름조금 $(3 \leq$ 전운량 $\leq 5)$, 구름 많 음 $(6 \leq$ 전운량 $\leq 8), \quad$ 흐림 $(9 \leq$ 전운량 $\leq 10)$ 으로 (디지털예보기획단, 2004), 그리고 전운량은 0 10 까지 11 단계로 나누어지며 이는 목측으로 관측되고 있다.

하늘상태 판정알고리즘은 수치모델인 RDAPS (Regional Data Assimilation and Prediction System)의 $850 \mathrm{hPa}, 700 \mathrm{hPa}$ 의 습수(기온과 이 슬점온도 차이)를 이용하는 NWP(Numerical Weather Prediction) 방안, 대기 상, 중, 하층 의 최대 상대습도를 이용하는 미 공군 방안인 AFWA(Air Force Weather Agency), 그리고 기 온과 습수를 이용하는 Arabey 방안 등이 있다[1]. $\mathrm{NWP}$ 방안은 기상청 기상예보관의 장기간 예보경험을 정량화한 방안으로 습수가 작으면 
구름이 형성되고 습수가 크면 구름이 소멸된 다는 간단한 원리를 이용한 것이다. 판정기준 이 되는 고도는 $850 \mathrm{hPa}$ 과 $700 \mathrm{hPa}$ 이다. 전운량 은 구름의 두께보다 구름의 수평적인 분포로 결정되므로, $850 \mathrm{hPa}$ 습수와 $700 \mathrm{hPa}$ 중 습수가 작은 값을 사용한다. 판정에 사용하는 습수의 기준 값은 $2^{\circ} \mathrm{C}$ 미만일 경우 흐림, $2^{\circ} \mathrm{C}$ 이상 $4^{\circ} \mathrm{C}$ 미만일 때 구름 많음, $4^{\circ} \mathrm{C}$ 이상 $6^{\circ} \mathrm{C}$ 미만일 때 구름조금 그리고 $6^{\circ} \mathrm{C}$ 이상일 때 맑음으로 판 정한다. 이 방안은 미 공군에서 습수를 이용하 여 운량을 판정하는 방법과 비슷하며, 맑음의 판정기준이 $\mathrm{AFWA}$ 의 기준 값보다 $1^{\circ} \mathrm{C}$ 높다.

$\mathrm{AFWA}$ 는 미국 대기과학연구소(NCAR)에서 개발한 중규모수치모델인 MM5(method built in the fifth-generation Mesoscale Model)의 후처리 패키지 중 하나인 그래픽소프트웨어 Grads에서 구현된 알고리즘으로, MM5의 예 보자료를 이용하여 전 운량(0 1 사이 값)을 산출하고 있다[2]. 이 방안은 대기를 3개 층으로 구분하여 각층의 최대 상대습도로 전 운량을 결정한다. 각층의 운량은 식 (1)과 (2)와 같다.

Table. 2 Estimation Algorithm of Sky

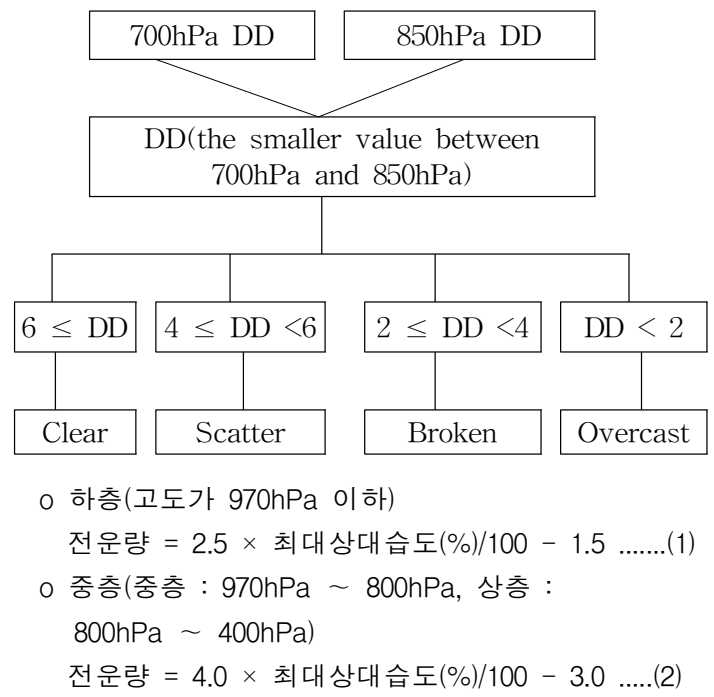

이 방안에 따르면 대기하층의 두께는 약 $350 \mathrm{~m}$ 로 설정되었으며, 전운량을 판정할 때 안개 효과를 고려한 것으로 보인다. 반면 상층의 상한 고도는 $400 \mathrm{hPa}$ 로 전운량 판정은 지상에서 $7 \mathrm{~km}$ 이내 대기만을 고려한다. 이 방안은 기온에 따라 구름이 발생하는 상대습도가 다른 점을 반영하 여, 상대습도가 같을 때 하층의 전운량을 상층의 전운량보다 크게 판정한다. 이 연구에서는 중층 과 상층에서 산출한 전운량 중 높은 값을 선택하 고, 선택한 전운량을 디지털예보시스템의 하늘 상태 구분기준에 근거하여 판정한다.

$\mathrm{NWP}$ 방안과 미 공군방안은 상대습도관련 기상요소만을 이용하여 하늘상태를 판정하므 로, 기온이 높을 때는 습수가 작아도 구름이 생기기 어렵고, 반대로 기온이 낮을 때는 습수 가 크더라도 구름이 쉽게 생기는 현상을 적절히 반영하기 힘들다. 이러한 한계를 극복하기 위하 여 기온과 상대습도를 동시에 고려한 Arabey방 안이 개발되었다. 이 방안은 습수와 기온을 동 시에 고려하여 Fig. 5와 같이 하늘상태를 4종 류로 판정한다(점선). 판정문턱 값은 기온 $0^{\circ} \mathrm{C}$ 이상, $0^{\circ} \mathrm{C} \sim-10^{\circ} \mathrm{C},-10^{\circ} \mathrm{C}$ 이하 구간으로 구 분하여 빙점, 과냉각 점별로 다르게 적용한다.

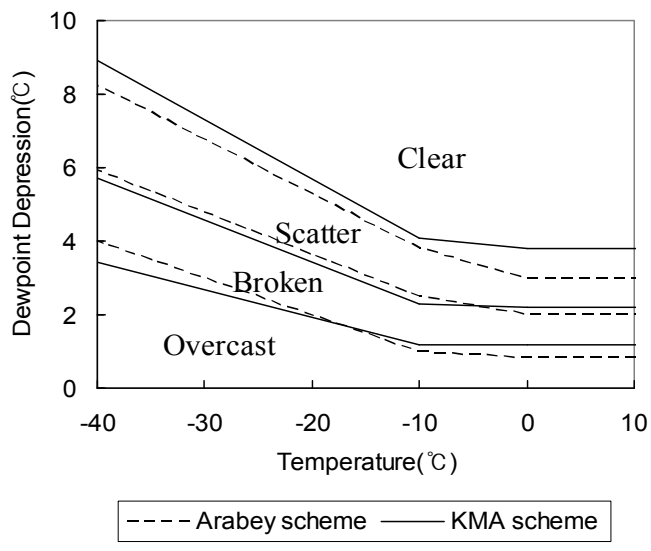

Fig. 5 Sky Estimation using a Arabey Method(Dot) and KMA Method(line) 
Arabey방안은 미국내 자료로 결정한 문턱 값을 사용하므로, 한반도에 적용할 수 있도록 한반도 관측 자료를 이용하여 판정문턱 값을 Fig. 5 실선과 같이 재설정하는 방안을 사용한 다('KMA방안').

$\mathrm{KMA}$ 방안의 판정문턱 값은 Arabey방안의 기온구간에 대하여 습수를 $0.1^{\circ} \mathrm{C}$ 씩 반복적으 로 변경하여 BIAS가 가장 작게 설정되었다.

본 연구에서는 Table 2 의 판정 알고리즘에 따 라 과거 운량 관측 데이터를 운량 예보 데이터와 같이 4 계를 가지는 시계열 데이터로 변환하여 태 양광 발전 예측에 사용하였다. 테이블 구조는 운 량 예보 데이터와 같이 wforecast 에 적재하였다.

\section{4 일출, 일몰 데이터}

태양광 발전 예측을 위해서는 태양이 뜨고 지 는 시각이 중요하다. 일출, 일몰 시각표는 한국 천문연구원에서 제공받을 수 있으며 과거 데이 터와 미래의 일출, 일몰 시각까지 구할 수 있다. 이를 이용하여 요구되는 예측일자의 동일 일출, 일몰시간을 추출하여 대상자를 확인한다.

\section{3. 태양광 발전 예측 알고리즘 구현}

\section{1 예측 알고리즘}

Fig. 6의 태양광 발전 예측에 사용된 알고리 즘은 $\mathrm{E}$ 연구원에서 운영 중인 태양광발전시스 템을 대상으로 약 2 년 이상 축적된 데이터를 이용하여 시계열 분석기법을 통해 계절별 시 간별 표준평균 데이터를 추출하여 적용하는 방법으로 개발하였다. 축적된 태양광 발전 데 이터는 데이터 마이닝 기법을 통해 데이터를 추출하고 정제하였으며, 시계열 분석기법을 통해 태양광 발전 예측 알고리즘 개발하였다. 일반적으로 시계열자료는 추세변동, 순환변 동, 계절적 변동, 불규칙 변동 등 4 가지로 구
성되고 기상데이터들은 이들 요소를 모두 고 려되기 때문에 분석하기가 매우 어렵다. 따라 서 계절지수를 구하기 위해 이동평균법을 이 용하여 생성하고, 불규칙변동에 대응하기 위 해 자료의 평할 화가 필요하며, 이동평균법, 지수 평할 법 등 여러 기법을 이용한다.[3][4] 본 연구에서는 기 구축된 발전 장비를 대상 으로 발전예보 시스템을 설계한 것이므로 측 정값 및 예보 값에 이미 공간요소를 포함하고 있어 공간요소를 고려하지 않았으며, 알고리 즘을 활용한 발전량 예측과정을 살펴보면 아 래와 같다. 하지만 미 측정 예정지를 대상으로 할 경우에는 지역 및 시간 그리고 고도에 따 른 일사량 값이 다르기 때문에 이러한 공간 속성을 고려하여야한다. 따라서 공간 시계열 자료를 분석하는데 있어 일반적으로 알려진 ARIMA 모형에 적합하여 분석을 행하면 공간 적인 정보를 반영하지 못하기 때문에 향후 연 구에서는 기존에 시간만을 고려한 시계열 분석 방법에 공간통계의 공간적 정보를 반영한 공간 시계열 모형인 공간시계열 자기회귀 이동평균 모형(STARMA)과 공간시계열 중 선형 모형 (STBL)형을 이용한 연구를 진행할 예정이다[5].

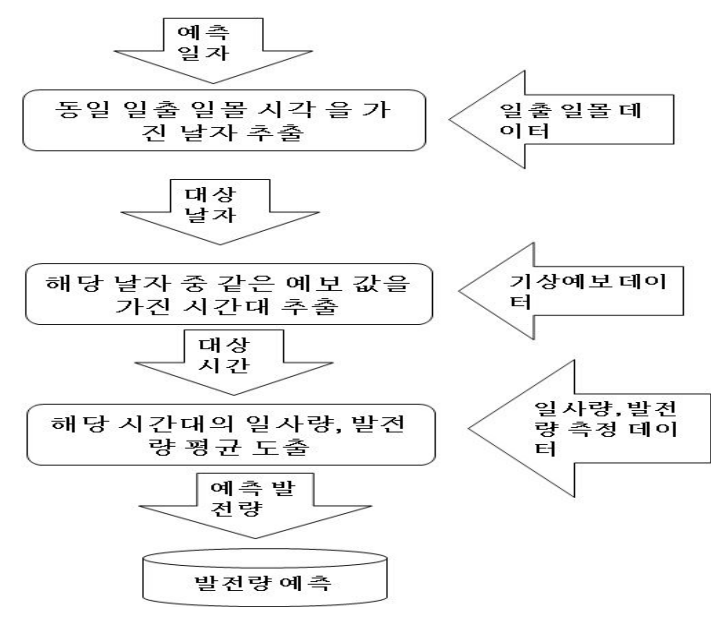

Fig. 6 Forecast Algorithm for Solar Power Generation 
(1) 대상 날짜 선정

예측하고자 하는 날짜와 과거 같은 환경의 날짜를 추출하기 위하여 일출, 일몰이 같은 날 짜를 먼저 추출한다. 가능한 한 많은 과거 데 이터의 확보가 예측의 정확성에 영향을 주게 된다.

따라서 본 연구에서는 많은 날짜를 확보하 기 위하여 일출, 일몰시각에서 +-2 분을 하여 데이터를 확보하였다.

$\mathrm{E}$ 연구원의 모니터링 데이터는 2010년 2월 부터 축적되어 있으며 지속적으로 운영되고 있어 정확한 일출, 일몰 시각으로 대상 날짜를 추출하는 것이 가능하다.

(2) 예보가 일치하는 날짜와 시간대 추출

일출, 일몰 시각이 같은 날짜를 대상으로 예측하고자 하는 날짜의 시간대별로 같은 운 량 예보 값을 가지는 날짜와 시간대를 추출 하고 이를 활용하여 발전량 테이블의 해당시 간대의 평균발전량을 이용하여 예측 값을 도 출한다. 예를 들어 2012년 8월 1일은 전 시간 대의 운량이 2: 구름조금으로 예보 되었다면, 일출, 일몰이 같은 날짜에 같은 시간대에 같 은 운량 예보 값을 가지는 날짜는 추출하는 것이다.

\section{(3) 예측 수행시간 및 주기}

태양광 발전 예측은 현재 기상청에서 예보 하는 금일 포함 3 일간의 예측을 기준으로 하 였다. 예측의 수행은 매일 새벽 03 시에 수행 되고 금일 이후의 이전 예측한 데이터를 제거 후 새로 예측을 하게 된다.

그 이유는 기상청에서 매 3 시간 간격으로 기상 예보 값을 변경함으로 어제 예측한 금일 의 기상 예보 값이 금일 새벽에 예보한 값과
다르기 때문이다. 예측한 일사량 값과 발전량 값은 Fig. 7의 p_forecast 테이블에 저장되고 일사량 측정테이블 env 와 발전량 측정테이블 rn_power 와 비교 분석이 가능하도록 구성하 였다. 발전량 예측은 연구원의 모든 태양광발 전 원을 대상으로 수행을 하였고 설비가 구축 된 기간 및 위치에 따라 예측 결과의 차이를 보인다.

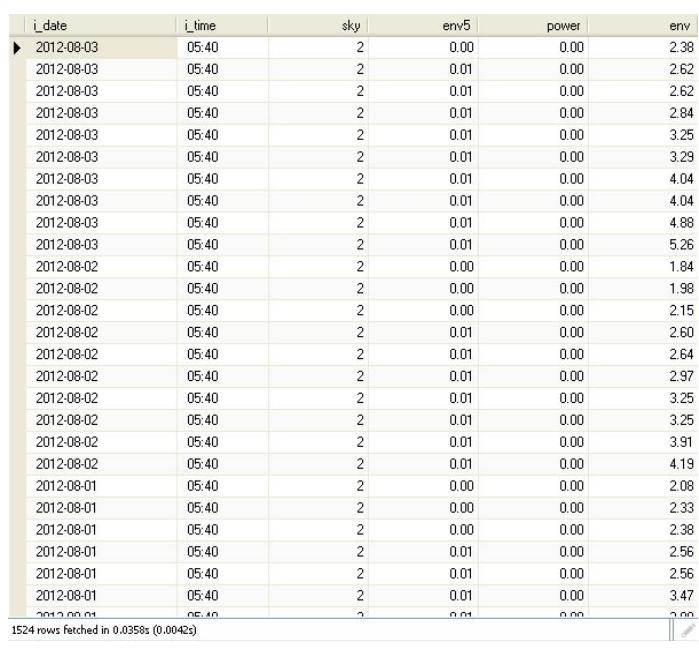

Fig. 7 Data of Radiation and Power Generation(p_forecast)

\section{(4) 일사량, 발전량 예측}

발전량 예측의 정확성을 기하기 위해 1 분 데이터를 활용하였고 I_time 당 10 개식의 데 이터가 추출한다. 따라서 총 1,524 개의 일사 량 및 발전량 데이터가 추출되고, 이 데이터를 10 분 단위로 평균을 낸 값으로 예측 일사량, 발전량을 계산한다. 본 알고리즘의 예를 위해 예측하고자 하는 날짜가 8월 1 일임으로 측정 값에 8월 1일 데이터가 포함되었으나 실제 예 측 시에는 당일자의 데이터는 포함되지 않게 된다. 아래 Fig. 8은 예측 알고리즘을 이용하 여 구현한 일사량과 발전량의 평균값을 화면 으로 표출한 발전량 예측 화면이다. 


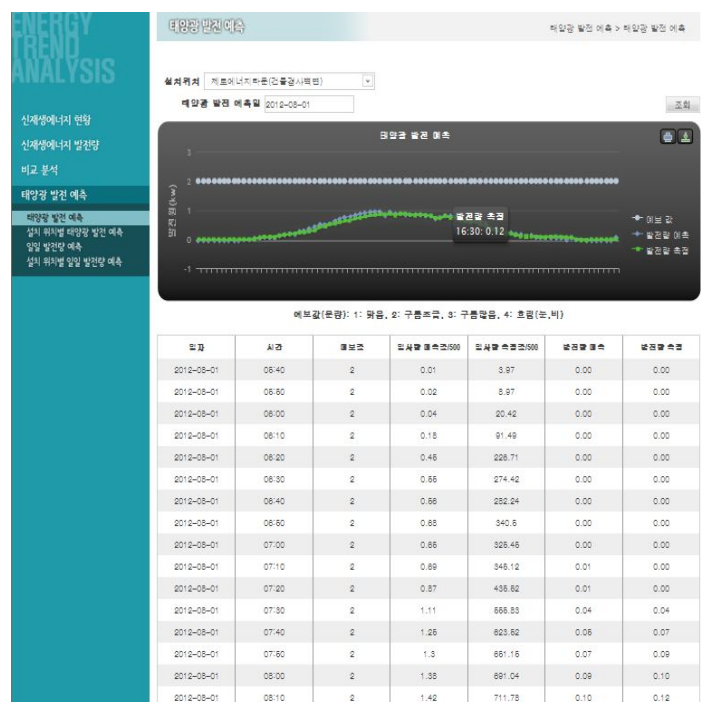

Fig. 8 Result of Predict Power Generation

\section{2 태양광 발전 예측 시스템 구현}

시계열 분석을 통해 예측된 태양광 발전량 은 $\mathrm{E}$ 연구원내 개별 발전 원 및 연구동별 예측 출력 값을 측정 발전량과 비교 분석할 수 있 도록 구현하였다.

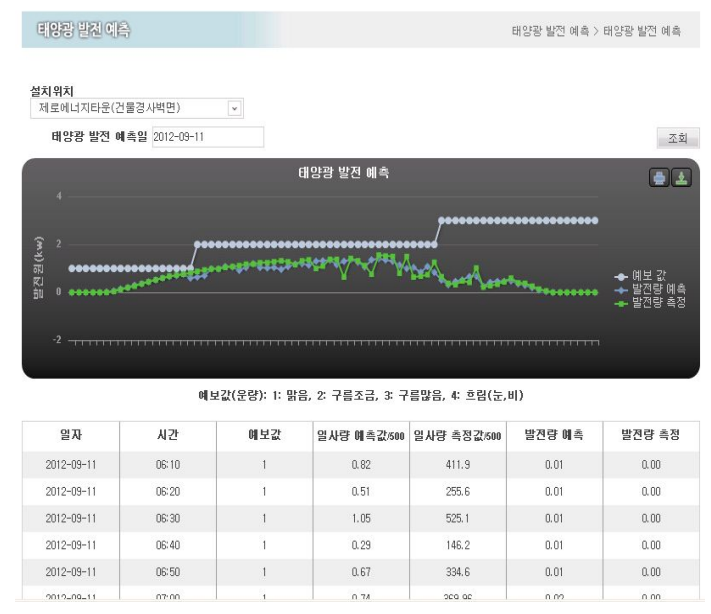

Fig. 9 Compare of Predict Result

Fig. 9는 $\mathrm{E}$ 연구원내 건물 경사벽면에 설치 된 태양광 설비에 대한 2012년 9월 12일 발전
량 예측 및 실 측정 값 비교 화면이다. 그림에 서 언은 운량 예보 값이며, 머선은 실 발전 량 그리고 선은 예측 값을 나타낸다. 이날 의 일출시각은 오전 06 시 10 분이며 9 시까지 운량 1: 맑음으로 예보되었다. 09시부터 15시 까지는 운량 2: 구름조금이며 이후는 운량 3: 구름 많음으로 예보되었으며 과거 관측한 시 계열 데이터를 활용한 예측 결과 값과 실 발 전량 값 매우 유사하게 나타남을 알 수 있다.

\section{4. 결 론}

본 연구에서 활용한 연구기반 데이터는 신 재생에너지 설비현황 데이터, 기상환경 데이 터, 발전량 데이터 3 가지로 분류된다. 기상환 경 데이터와 발전량 데이터는 비교 분석이 가 능하도록 1 분, 10 분, 일 단위로 정렬하여 동 시간, 특정시간대의 비교 분석이 가능하도록 하였다. 기상환경 데이터는 $\mathrm{E}$ 연구원내 풍향, 풍속, 일사량 데이터와 기상청의 예보데이터 (RSS 서비스 이용) 및 한국천문연구원의 일 출, 출몰, 박명시각 데이터로 구성되어있다. 여기서 제시한 태양에너지 예보 모텔은 기상 청의 예보를 기준으로 설계되었기 때문에 금 일 포함 3 일간의 예측이 가능하다. 발전량 예 측에서는 2010년 2월 이후 측정된 발전량 데 이터와 일사량, 일출, 일몰 데이터, 과거 기상 예보 자료를 바탕으로 한 예측 알고리즘을 적 용하였다.

현시점에서 태양광, 태양열 발전량이 기저 전력 공급에 미치는 영향이 미미하여 단기예 측으로도 충분하나 향후 전력의 공급과 관련 하여 중장기적인 예상 가능한 신재생에너지 발전량의 예측은 스마트 그리드에 연계되어 장단기 공급계획의 수립에 필요한 요소가 될 것으로 예상된다. 이와 관련하여 기상환경에 
따른 일 생산량, 계절별 생산량, 연 생산량에 대한 중장기 예측의 신뢰성을 높이기 위해 시 공간 시계열 예측이론, 신경망 학습이론 등을 적용한 다양한 연구가 요구된다.

\section{후 기}

본 연구는 한국에너지기술연구원 연구비지원으 로 수행되었음(과제번호 : GP-2012-0023)

\section{참 고 문 헌}

1. Kim, Yun Jai, "Study on the Application of Next-Generation Satellite Data(III)", Research Report KMA, 2007.

2. http://www.mmm.ucar.edu

3. Chang Gu Kang, "Compare Analysis for Time Series Forecasting Methods", Quarterly National Account, Vol.3 No.26, pp.80-105, 2006.

4. Sung Duck Lee et al. "Kalman-Filter Estimation and Prediction for a Spatial Time Series Model", CSAM(Communications for Statistical Applications and Methods), Vol.18 No.1, pp.78-87, 2011.

5. Sung Duck Lee et al, "A Comparison on Forecasting Performance of STARMA and STBL Models with Application to Mumps Data", The Korean Journal of Applied Statistics, Vol.20 No.1, pp.91-102, 2007. 